\title{
PRESENCIA Y FUNCIÓN DE LOS MITOS CLÁSICOS EN LA HISTORIA GENERAL Y NATURAL DE LAS INDIAS DE GONZALO FERNÁNDEZ DE OVIEDO Y VALDÉS
}

SANTIAGO FABREgat Barrios

\section{RESUMEN}

El presente artículo constituye una primera aproximación al estudio de las referencias mitológicas presentes en la Historia general y natural de las Indias de Gonzalo Frenández de Oviedo (1478-1557). Tras la presentación de las fuentes esenciales que alimentan el caudal mitológico disperso a lo largo de la obra magna del cronista, analizamos el uso que los mitos clásicos se hace en ella, a partir de tres ejes fundamentales: función retórica, función política y función descriptiva de los referentes mitológicos.

\section{INTRODUCCIÓN}

Pese a lo aparentemente tópico de la afirmación, no son muchos los autores de nuestro ya de por sí intrincado siglo XVI cuya vida y obras ofrezcan al estudioso la extraordinaria y variada complejidad que se aprecia en el caso de Gonzalo Fernández de Oviedo (1478-1557).

Presentado habitualmente como pionero en la crónica de Indias, Oviedo es además genealogista, historiador de la España de su época, buen conocedor de la heráldica, novelista de vocación breve y sobre todo protagonista de una sorprendente y extensísima singladura vital que él mismo, en compañía del destino, se encargó de ir completando durante más de setenta y nueve años de andanzas entre dos mundos'.

\footnotetext{
1 El estudio de su biografía ha sido abordado, entre otros, por Amador de los Ríos (1851); Pérez de Tudela (1957, 1959); De la Peña Cámara (1957); Ballesteros Gaibrois (1958, 1981); Otte (1958, 1959, 1982); Uría Riu (1960) y Gerbi (1978).
} 
De orígenes modestos, Gonzalo Fernández de Oviedo y Valdés, natural de Madrid, inició su formación en la casa de los duques de Villahermosa, desde la que pasó al servicio del príncipe don Juan, primogénito de los reyes Fernando e Isabel, en cuya casa y corte principesca sirvió hasta el fallecimiento en 1497 del malogrado heredero ${ }^{2}$. Disuelta la corte, llegarían los años de su periplo italiano - 1499 a 1502 - en los que el joven Oviedo, al servicio de distintos señores - Ludovico Esforza, el cardenal Juan Borja, Isabel de Aragón - , tuvo la oportunidad de viajar por la Península y Sicilia y tomó contacto con la literatura italiana del Renacimiento.

De regreso a España, desempeñó las tareas de notario y escribano público, hasta que en 1514, enrolado en la multitudinaria expedición de Pedrarias Dávila, pasó a las Indias con los cargos de escribano y veedor de las fundiciones de oro del Darién. Desde este momento, su epicentro vital se trasladará al otro lado del Océano, aunque fueron frecuentes sus estancias en España, las más de las veces motivadas por asuntos políticos o editoriales. En 1532 fue nombrado Cronista de Indias por Carlos V y desde 1533 hasta su muerte residió en la ciudad caribeña de Santo Domingo, de cuya fortaleza fue alcaide.

Su obra, de acentos variados y extraordinaria extensión, plantea hoy día aún no pocos problemas mayores - esclarecimiento de atribuciones dudosas, extensión real de algunos de sus escritos y edición de varios de ellos - , que la crítica especializada deberá ocuparse de ir resolviendo con el tiempo ${ }^{3}$.

En este contexto de lo excesivo e inabarcable con el que habrá de toparse todo aquel que desee acercarse con cierta profundidad a la vida y obras de Gonzalo Fernández de Oviedo, poco parece aportar a la contemplación global del personaje el estudio de un aspecto menor como es el de la alusión mitológica, máxime si se pretende atender a ella en la inmensa fronda de su gran obra, la Historia general y natural de las Indias.

$\mathrm{Y}$, sin embargo, no pocas veces descubrimos en los pequeños detalles la visión esclarecedora de aquellos acentos que vienen a confirmar o rebatir las apreciaciones generales que tenemos acerca de la personalidad y estilo de un determinado autor.

El caso de Fernández de Oviedo es además bien particular. Personalidad compleja y conflictiva, no han faltado aquellos que, guiados por el padre Las Casas, su encarnizado detractor, prestaron oídos a intencionadas dudas acerca de la solidez de su formación, puyas que incidían especialmente en un pretendido desconocimiento de la lengua latina que el dominico sevillano se ocupó de airear siempre que pudo.

Sobre el bagaje clásico de Fernández de Oviedo, bien puede afirmarse que su estancia en la corte del príncipe don Juan debió proporcionarle una erudición más bien escasa. Pese a la imagen de estrecha relación con el príncipe que algunos biógrafos de Oviedo - entre ellos Amador de los Ríos (1851) y Ballesteros (1981) - se han esforzado en transmitimos, no resulta ni siquiera probable que Oviedo asistiese junto a don Juan a las lecciones diarias que el heredero recibía del catedrático salmantino Fray Diego de Deza, en las que, lógicamente, la lengua latina formaba parte esencial del programa de

${ }^{2}$ Sus años en la corte castellana, retratada en su pulso diario y cotidiano, quedarán recogidos años más tarde en un precioso tratado de innegable valor documental: el Libro de la Cámara Real del príncipe don Juan (1548).

${ }^{3}$ Acerca de estos problemas de ámbito general que afectan a la obra del cronista ya escribimos en un trabajo anterior (FABREGAT: 2003). 
estudios, pues conocemos por el propio Fernández de Oviedo que estas clases tenían lugar en la absoluta privacidad entre maestro y discípulo ${ }^{4}$.

Sí le facultó sin duda la experiencia cortesana para obtener las credenciales y mimbres suficientes que le permitirían desenvolverse, una vez disuelta la corte del príncipe, por la Italia del primer Cinquecento. Son los años que Gerbi (1978: 161) denominó «los años decisivos, del vigésimo primero al vigésimo cuarto de su vida, que coincidieron con el periodo del pleno, maduro y triunfante Renacimiento en Italia». Durante aquel trienio Oviedo aprenderá el toscano y adquirirá una biblioteca personal que le acompañará hasta el fin de sus días, allá en la fortaleza caribeña de La Española ${ }^{5}$. Como afirmó Gerbi (1978:179), «la presencia de Italia se advierte a cada paso en los escritos del cronista».

Visto hoy Oviedo con nuestros propios ojos, y sin entrar a juzgar su latinidad - sin duda mucho más solvente que la señalada por Las Casas-, comprobamos cómo Oviedo se asoma en sus escritos, a través de diversas fuentes, a un buen número de autores clásicos; entre ellos, Aristóteles, Teofrastro, Cicerón, Diógenes Laercio, Ovidio, Virgilio, Tito Livio, Lucano, Plutarco, Tolomeo, Estrabón y sobre todo Plinio, fuente indispensable para entender la estructura y gestación de su gran Historia.

Como consecuencia de su formación y lecturas, la alusión a los mitos de la antigüedad greco-latina está presente en su obra y muy especialmente en la Historia general y natural de las Indias, eso sí, con ecos y funciones muy particulares, como corresponde a su doble actitud ante las fuentes clásicas, de respeto por una parte, pero crítica por otra, cuando el saber de la Antigüedad queda invalidado por el supremo valor de la experiencia que procede de los nuevos descubrimientos geográficos y científicos.

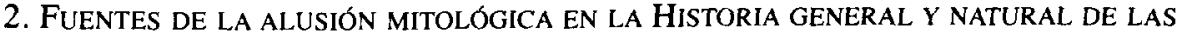 INDIAS}

En agosto de 1532, tras previa petición del Consejo de Indias, quedaba otorgado a Fernández de Oviedo el título de cronista de Indias:

«Bien es lo que decís que se escriban las cosas de las Indias para que haya memoria dellas, y pues os parece que Gonzalo Hernández de Oviedo lo hará bien, por haber estado tanto tiempo en aquellas partes, por la excelencia y noticia que tiene de las cosas dellas, dadle el cargo dello, con tanto que antes que se imprima ni publique lo que escribiere, presente ante Nos una copia dello para lo que mandemos ver; y por su trabajo yo he por bien que se le den 30.000 mill maravedíes en cada un año de los que en ello

${ }^{4}$ Libro de la Cámara Real del príncipe don Juan, ed. Fabregat (2001: 299). Es preciso tener en cuenta que Fernández de Oviedo desempeño en la corte el doméstico oficio de mozo de cámara, alejado de las dignidades y prerrogativas que se reservaban a otros jóvenes, los pajes del príncipe, hijos de los más encumbrados linajes de Aragón y Castilla.

${ }^{5}$ Como tendremos la oportunidad de ver, la biblioteca del cronista ha sido estudiada por Tumer (1971). Por las obras de Oviedo desfilan autores italianos como Dante, Petrarca, Bocaccio, Francesco Fidelfo, Leonardo Aretino o Ariosto. Tuvo además el joven Oviedo la ocasión de conocer personalmente a Leonardo da Vinci, Jacopo Sannazaro, Pontano, Serafino dell Aquila y de entablar, años más tarde, una fructífera relación epistolar con el cardenal Pietro Bembo. 
entendiere y ocupare, librados en las rentas de aquellas partes; proveedlo así, y que pues se le ha de dar este salario, escriba las cosas de las dichas Indias complidamente y por buen estilo" 6 .

Seis años antes, en 1526, Oviedo había dedicado a Carlos V el Sumario de la natural historia de las Indias ${ }^{7}$, breve tratado compuesto de ochenta y seis capítulos, en cuyo prólogo el cronista hacía promesa al Emperador de una obra de carácter más extenso y detallado en la que Oviedo se encontraba trabajando ya desde hacía unos años.

Los desvelos del cronista habrían de fraguar en la edición de la primera parte de la Historia general y natural de las Indias, que en 1535 sale de las planchas sevillanas de Jacobo Cromberger ${ }^{8}$.

El ambicioso proyecto, que comprende un total de cincuenta libros, se divide en tres partes distintas, en las que Oviedo entremezcla la historia general y la natural, haciendo gala de un estilo sencillo - común y llano, como lo define el propio autor--, en el que sin embargo tiene frecuente cabida la cita erudita, conforme a las convenciones de las exitosas misceláneas y silvas, tan en boga en nuestro siglo XVI.

Fuente esencial de la Historia es la propia experiencia, primacía de la comprobación empírica que entra a menudo en disputa con la autoridad de sus modelos antiguos. En este aspecto, como en tantos otros, Oviedo encarna a la perfección la mentalidad del intelectual español de su tiempo: una doble actitud ante los redescubiertos clásicos le hace seguir unos modelos, «convencido (...) de que las fuentes de la verdadera ciencia se hallaban en los textos de la Antigüedad», mientras, de otra parte, le impulsa a alzarse contra la autoridad «del magister dixit como criterio de certidumbre» (Laín Entralgo, 1979: 216), especialmente en aquellos casos en los que la realidad y la experiencia le muestran, clara y distintamente, que las enseñanzas de los antiguos han de ser revisadas. Lejos de encontrar contradicción en su doble actitud, Oviedo se apresta a señalarla en el mismo Plinio, pues también su maestro «acrescentó algunas cosas que los antiguos no las entendieron, o después la vida las falló» ${ }^{9}$.

En el terreno de la alusión mitológica, el que hoy nos ocupa, la Historia general y natural de la Indias se alimenta de fuentes variadas y diversas. Lógicamente, resulta complicado en un trabajo de la naturaleza de éste señalar con absoluta precisión y detalle las fuentes mitológicas presentes en una obra de la extensión y complejidad de la Historia general y natural.

La pretensión ideal de señalar qué obras y autores se citan de manera directa y qué otros se mencionan a través de la transmisión indirecta que procede fundamentalmente de los textos latinos medievales, topa no sólo con el inconveniente que plantea la enorme extensión de la obra estudiada, sino también con factores tales como la propia com-

${ }^{6}$ Archivo General de Simancas. Secretaría de Estado, leg. 636. Apud. Pérez de Tudela (1959: CXVIII).

${ }^{7}$ La obra se conoce bajo dos títulos distintos: De la natural historia de las Indias y Sumario de la natural historia de las Indias (Toledo, Ramón de Petrás, 1526).

${ }^{8}$ Historia general y natural de las Indias, islas y Tierra Firma del mar Océano. De sus tres partes, en vida de Oviedo sólo se publicó la primera, dividida en diecinueve libros, y el libro vigésimo, acerca de los viajes y descubrimientos de Magallanes (Valladolid, 1557). La primera edición completa es la de Amador de los Ríos (1851). En citas sucesivas, [HGNI].

${ }^{9}$ [HGNI, Libro I, cap. I, ed Pérez de Tudela (1959: vol. I, 11). 
plejidad de un cotejo exhaustivo entre citas y autores o el carácter no absolutamente fiable de los escasos trabajos hasta ahora publicados sobre las fuentes bibliográficas manejadas por el cronista ${ }^{10}$.

Como es bien sabido, la transmisión de la materia mitológica en la España de los siglos XV y XVI procede fundamentalmente de los testimonios latinos. Siendo además Fernández de Oviedo un desconocedor absoluto del griego y dada la escasez casi total por aquel entonces de manuscritos y ediciones accesibles en esta lengua, su aproximación a autores como Homero, Hesiodo, Platón o Aristóteles se produce siempre a través de fuentes indirectas, esencialmente medievales.

En el caso de Homero, las alusiones al ciclo troyano proceden en Oviedo fundamentalmente de los relatos de Dictis Cretense y Dares Frigio, «cuyo éxito en la Edad Media está justificado por motivos bien conocidos por todos - estar escritos en latín, en prosa, no en verso y por tanto con más visos de credibilidad, y presentados como relatos históricos, desprovistos de todo el aparato mitológico de los poemas griegos-» (Arcaz, 2002: 2). Según apunta Turner (1971: 158), Fernández de Oviedo manejó la edición de De bello graecorum contra troyanos impresa en Basilea (1529) por Andreas Cratander.

Muy probablemente, Oviedo debió contar además con la traducción de la llíada de Juan de Mena y con la Crónica troyana traducida por el Canciller Pero López de Ayala, dos autores castellanos que le eran suficientemente conocidos y por los que Oviedo manifestó siempre su admiración y gusto.

En que respecta a la Odisea, texto cuya difusión en España fue más tardía, las frecuentes alusiones, relacionadas siempre con episodios sumamente conocidos - Circe, los Cíclopes, los Lestrigones, el tejer y destejer de Penélope-, parecen proceder de fuentes latinas medievales, algunas de ellas identificadas por el propio autor, caso de las Etimologias de San Isidoro" ${ }^{11}$.

Entre las fuentes latinas directas, destacan esencialmente dos: las imprescindibles Metamorfosis de Ovidio, citadas en numerosas ocasiones a lo largo de la Historia general y natural, y la Historia natural de Plinio, verdadero maestro y norte de Fernández de Oviedo en todo aquello que concierne a la descripción natural de las nuevas tierras ${ }^{12}$.

Oviedo emplea además las Geórgicas de Virgilio, las Décadas de Tito Livio y deja entrever su conocimiento, casi siempre a través de «florilegios o de traducciones italia-

${ }^{10}$ Nos referimos en concreto al estudio de Tumer (1971), que empleamos como guía, aunque con fundadas reservas. Por todas las razones arriba expuestas, el estudio de las fuentes mitológicas de la Historia general y natural de Fernández de Oviedo se plantea en este trabajo como una primera aproximación, no exhaustiva.

1 Véase [HGNI], Libro VI, cap. L (ed. Pérez de Tudela, 1959: vol. 1, 219).

${ }^{12}$ Según Turner $(1971: 174,177)$, Fernández de Oviedo manejó a ambos autores en ediciones toscanas. En el caso de Ovidio, se apunta hacia la edición veneciana de 1522, a cargo de Georgi Rusconi, pues la primera edición en castellano es del año 1542. Para Plinio, Turner concede crédito a las denuncias de Las Casas y propone la edición también veneciana de Zani Portesio de 1489, también en toscano y traducida por Cristóforo Landino. Personalmente, me inclino a pensar que Oviedo manejó a ambos autores en latín. Las Metamorfosis eran obra bien conocida, fuente además ampliamente tratada en textos manejados por Oviedo, como la General Estoria de Alfonso X (Arcaz, 2002: 12). En cuanto a la Historia natural, hay que señalar que en sus Quinquagenas de la nobleza de España (1544-1556) Oviedo cita a Plinio directamente en latín. 
nas o españolas» (Gerbi, 1978: 183), de otros clásicos grecolatinos, caso de Hesiodo, Tucídides, Teofrastro, Ptolomeo, Estrabón, Lucano, Luciano o Apuleyo ${ }^{13}$.

En cuanto a las fuentes latinas medievales, es preciso comenzar destacando el peso de las Etimologías isidorianas, abundantemente citadas en la Historia, y a través de las cuales el cronista tuvo conocimiento de las teorías exegéticas de Evémero ${ }^{14}$.

Por otra parte, el empleo de las llamadas historias generales sirve a Fernández de Oviedo para documentar y adaptar a sus fines aquellos mitos que «abordan la historia más remota de la Península» (Caballero López, 2002: 3), en una línea nacionalista y de apología monárquica similar a la que se aprecia en un Jiménez de Rada - Historia de rebus Hispaniae - . Además de a la obra de El Toledano, recurre Oviedo a la cita de Alonso de Madrigal, El Tostado y, ya en el terreno de la historiografía vernácula, a la General Estoria del Rey Sabio.

No debe olvidarse además que el contacto de Fernández de Oviedo con la literatura romance de su tiempo es mucho más rico de lo que a menudo ha venido señalándose ${ }^{15}$ y comprende a autores tanto italianos como españoles, entre los que merece especial atención su admirado Petrarca, citado y comentado en varias de las obras del cronista, amén de otras figuras de la talla de Dante o Bocaccio, del que Oviedo fue traductor ${ }^{16}$, o los españoles Jorge Manrique, Íñigo López de Mendoza, Juan de Mena, Pedro de Cartagena o el propio Juan Boscán. También a través de ellos llegaron los ecos de la mitología clásica a la Historia general y natural de las Indias.

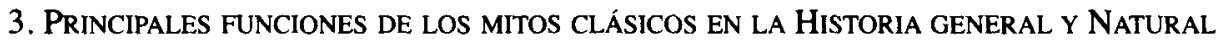 DE LAS INDIAS}

\subsection{Función retórica del mito}

El extensísimo legado escrito de Gonzalo Fernández de Oviedo nos ha proporcionado un solo testimonio encuadrable en la literatura de ficción. Nos referimos a su novela caballeresca Don Claribalte ${ }^{17}$, obra en la consabida tradición de la novela de

${ }^{13}$ De Diodoro Sículo manejaría, según Turner (1971: 158), la Diodori historiarum priscarum a Poggio in Latinum traducti.

I4 Tal como afirma Caballero López (2002: 2) al respecto del papel de San Isidoro como difusor del evemerismo, «después del hispalense no habrá cronista que omita la insercjón en sus historias unjversales de dioses y héroes míticos humanizados». El caso de Fernández de Oviedo es un tanto particular, como tendremos la oportunidad de ver.

${ }^{15}$ Sobre este aspecto hemos trabajado en nuestra tesis doctoral (Fabregat, 2001: 40-53).

${ }^{16}$ Se trata de la traducción de El Corbaccio que en 1546 salió en Sevilla de las planchas de Andrés de Burgos con el título de Laberinto de amor.

${ }^{17}$ Gonzalo Fernández de Oviedo, Libro del muy esforzado e invencible cavallero de la fortuna propiamente llamado Don Claribalte, que según su verdadera interpretación quiere dezir Don Félix o bienaventurado. Nuevamente impreso e venido en esta lengua castellana: el qual procede por nuevo e galán estilo de hablar, Valencia, 1519. Existe una edición facsímil: ed. Real Academia Española (1956); y dos ediciones recientes: Río Nogueras (2001) y la edición crítica de Rodilla León, María José (2002). 
caballerías, cuyo inverosímil argumento queda justificado, en opinión de su autor, a través de la gracia de estilo.

Años más tarde, ya desde la publicación del Sumario (1526), el giro erasmista que experimenta Fernández de Oviedo le lleva no sólo a repudiar su ópera prima y con ella a todo el género de caballerías, sino también a postularse como defensor de un estilo común y llano, desnudo de ornato retórico ${ }^{18}$.

Así, al dedicar la Historia general y natural a Carlos V, en el proemio del Libro primero escribe:

«Quiero certificar a Vuestra Cesárea Magestad que irán desnudos mis renglones de abundancia de palabras artificiales para convidar a los letores; pero serán muy copiosos de verdad, y conforme a ésta, diré lo que no terná contradicción, cuanto a ella, para que vuestra soberana clemencia allá lo mande polir e limar. Con tanto que del tenor e sentencia de lo que aquí fuere notificado a vuestra grandeza, no se aparte la intención y obra del que tomare cargo de enmendar la mía, diciéndolo por mejor estilo» ${ }^{19}$.

Este deseo de hacer una prosa arrimada no tanto «a la eloquençia e dulçura de palabras, ni contentamiento de las orejas del vulgo e ornamento retórico, quanto a la puridad e valor de la verdad, llanamente e sin rodeos ni abundançia de palabras ${ }^{20}$ choca en la Historia general y natural con las exigencias del cargo de cronista de Indias, pues Oviedo relata los hechos ante su propio rey - «dico ego opera mea regi ${ }^{21} »-$ y es muy consciente de que su obra será recibida con cierto escepticismo crítico en los círculos cortesanos, donde su cartel como hombre de letras dista mucho del prestigio reconocido en su día a un Pedro Mártir, por mencionar a su más docto y latino predecesor.

Por todo ello, a lo largo de la Historia, Fernández de Oviedo acude con frecuencia a la cita culta, al tiempo que se afana en buscar, no sin cierta artificiosidad, el refrendo de clásicos y medievales, aunque en no pocos momentos sólo consiga con ello apartar al lector del natural hilo discursivo de los acontecimientos.

En este contexto, la inserción retórica de la cita de carácter mitológico en la Historia de Oviedo no es sólo moda literaria, sino también deseo de justificar su erudición ante un tan poderoso mecenas como el propio Emperador, actitud ésta que es igualmente apreciable en otros autores cortesanos de formación autodidacta, como es el caso de Juan del Encina (Kidd, 2002: 18).

De este modo, la alusión mitológica cobra entre otras una función de carácter retorico que, sin ser primordial ni única, sí se toma importante a lo largo de la Historia ge-

${ }^{18}$ Tal como señalan López Grijera (1995: 63) y De Lama (1999: 143), el «escribo como hablo» valdesiano y el «huir la afetación» tienen contraída una importante deuda con las teorías erasmistas sobre el estilo, ya expuestas por Erasmo en De conscribendis epistolis (1522), con anterioridad pues a la publicación de la traducción española de El cortesano (1534).

${ }^{19}$ [HGNI], Libro I, cap. I, ed. Pérez de Tudela (1959: vol. I, 9).

${ }^{20}$ Gonzalo Fernández de Oviedo, Libro de la Cámara Real del príncipe don Juan, ed. Fabregat (2001: 433-434).

${ }^{21}$ [HGNI], Libro II, cap. I (ed. Pérez de Tudela, 1959: 14). Al menos ésta es la declaración inicial de intenciones de Fernández de Oviedo, pues, a lo largo de la obra, son abundantes las alusiones directas al lector - general y anónimo - y no sólo al español, en una clara muestra del carácter de difusión general y europea que Oviedo quiso imprimir a su Historia. 
neral y natural y discurre por cauces muy similares a los del uso del argumento de autoridad en el texto.

Con todo, el conocimiento del mito que demuestra Fernández de Oviedo es a nuestro juicio más profundo que el apreciable en no pocos de los autores españoles de la anterior centuria, en cuyas obras las consabidas listas de personajes - que entremezclan el mito con lo histórico y lo bíblico- constituyen el núcleo esencial de los referentes mitológicos aludidos (Arcaz, 2002: 9), tendencia ésta que en Oviedo se manifiesta sólo como un recurso marginal y de limitado interés para el crítico.

Destacaremos seguidamente algunos de estos usos esencialmente retóricos del mito, presentes en la Historia general y natural de las Indias.

La antonomasia. El uso por antonomasia de los nombres de personajes mitológicos, simbolizando a través de su simple mención la cualidad esencial por la que se les recuerda, suele estar ligado a un conocimiento del mito por lo general superficial, que procede de fuentes indirectas, cuando no de la simple instrucción «por oídas». En la Historia de Oviedo su empleo es relativamente reducido, aunque presente en determinados pasajes y semblanzas.

Así, al describir el cronista madrileño al conquistador Diego de Almagro, escribe:

«El ser de su persona era tan valeroso cuanto pensarse puede; su esfuerzo no mediocre, sino de un Alcides o Perseo, o el que quisieren escoger de aquellos famosos Hércoles, igualándose a los muy famosos, señalados e osados varones, antiguos militares» ([HGNI], Libro ILVII, proemio, ed. Pérez de Tudela [1959: vol. V, 127]).

Usada con cierto humorismo sarcástico, vemos aparecer la antonomasia en el relato de las costumbres de los indios guerreros de Venezuela, que, según Oviedo, adornaban sus cuerpos de por vida con pinturas identificativas de sus hazañas bélicas, proceder éste que le hace recordar al cronista nobles hábitos caballerescos:

«Y aquestos indios que así están alcoholados son estimados por una gran dignidad, e no hay más que ser ni más honra que alcanzar: que paresce que este tal es un Héctor, o un Bernardo del Carpio, o un Cid Ruy Díaz, o quien más quisierdes estimar» ([HGNI], Libro XXV, cap. XIX, ed. Pérez de Tudela [1959: vol. III, 53]).

La captatio benevolentiae. Concentrado su uso, como es esperable, en los prólogos o proemios que encabezan los distintos libros - en los que lógicamente la figura de Carlos V como destinatario se hace mucho más patente - la inclusión de lo mitológico suele contribuir a la elaboración y consecución de la captatio, que a menudo se articula en torno al tópico ars longa, vita brevis. En efecto, larga es la materia de Indias para ser descrita e historiada por un solo hombre en una sola vida:

«E faltará el tiempo e la pluma e las manos e la eloquencia, no solamente a mí, mas, aquellos famosos poetas, Orpheo, Homero, Hesiodo, Píndaro, no pudieran bastar a tan encumbrada labons ([HGNI, Libro L. VI, cap. VIII, ed. Pérez de Tuedela, 1959: vol. I: 158). 
Similar a la cita anterior, esta vez enriquecida con el uso amplificado de la antonomasia, la encontramos en el proemio del misceláneo Libro de los Depósitos:

«(...) dándome a mí por ejercicio, en esto que escribo, una materia tan famosa e alta e copiosa, que la vida del antiguo Néstor, que tanto supo e tanto vivió -como dice Francisco Petrarca-, con la aquel rey gaditano llamado Argantonio, no fueran tan largas, juntadas con la mía, o acrescentándose las dos en el número de mis años, que pueda yo llevar a cabo lo que se puede escribir en este caso» ([HGNI], Libro L. VI, proemio, ed. Pérez de Tuedela, 1959: vol. I: 142$)^{22}$

Otras veces es el tópico de modestia el empleado por Fernández de Oviedo para despertar las simpatías del lector, sacando a colación la pretendida escasez de su ingenio aplicado a tan vasta materia como es la crónica de Indias, aunque pese a ello no dude en hacer alarde erudito citando sucesivamente a Cicerón y Petrarca:

«Oh fortunado, oh dichoso mancebo, que hallaste a Homero por pregonero de tus virtudes». Conforme a esto, Francisco Petrarca, en uno de sus amorosos sonetos, dice:

"Gionto Alexandro a la famosa tomba

del fiero Achile, sospirando disse:

o fortunato, che si chiara tromba

trovasti, e chi di te si alto scrisse»

(...) Estas palabras de Alejandre muestran la envidia que hobo de haber tenido Aquiles tan alto escriptor para su historia, e que él para la suya no tenía tal cronista; porque en la verdad, el estilo y elocuencia del autor de una famosa historia mucho la engrandesce e sublima (...) Esto falta aquí por cierto, e yo confieso que por tantas e tales e tan diversas materias como son de las que yo aquí tracto, fuera nescesario otro ingenio que el mío» ([HGNI], Libro L. XXXI, proemio, ed. Pérez de Tudela, 1959: vol. III: $362-363)^{23}$.

La alusión erudita. Pese a ese «irán desnudos mis renglones» con el que veíamos que Fernández de Oviedo se dirigía a Carlos V, el estilo del cronista no está - salta a la vista - ni mucho menos exento de ornamento retórico y erudito. Ya sea por el carácter oficial de la Historia, ya por ser consciente su autor de que sería la obra por la que habría de recordársele, Oviedo acude frecuentemente a alusión erudita, en la que tienen cabida tanto lo estrictamente mitológico como las referencias a enclaves y lugares de la geografía clásica.

${ }^{22}$ Idéntico argumento, ahora con la alusión al bíblico Matusalén, se repite en el proemio del libro XXII. Como hemos apuntado, la mención por antonomasia no se reduce en exclusiva a los personajes mitológicos, sino que incluye asimismo referentes históricos y bíblicos.

${ }^{22}$ En diversos pasajes de sus obras gusta Oviedo de citar, glosar e incluso imitar - con escaso acierto, esto último - a Petrarca. El soneto mencionado es el CLXXXVII: «Cuando Alejandro vio la sepultura», Cancionero, ed. Crespo (1988: 184). 
El rasgo de estilo, común en la época, se reviste en el caso de Oviedo de ciertos tintes de necesidad, pues una obra del carácter de la Historia resultaba, aún a estas alturas del siglo XVI, mucho más esperable en latín que en una lengua vernácula como el castellano. Las posibles críticas - evidentemente centradas en su deficiente latinidad - que Fernández de Oviedo recibiese por ello bien podían quedar acalladas a través de una abundante presencia de lo erudito en la Historia. De este modo, quedaba además reforzada la vehemente defensa, tantas veces emprendida por Oviedo, del idioma castellano, lengua - en su opinión - parangonable en todo a las tres clásicas y válida por tanto para el tratamiento de la historia.

Así, echando una mirada al Mundo Antiguo justo en el momento de estar describiendo el Nuevo, el cronista compara, a través de El Tostado, «los navíos o barcas de los indios, que ellos llaman canoas, e en algunas partes las dicen piraguas» con la barca de Deucalión (Libro VI, cap. IV, vol. I: 149-150); menciona a Ganímedes, como copero de Júpiter, al respecto de las creencias extraterrenas de los indios de la Castilla del Oro ( $\mathrm{Li}$ bro XXIX, cap. XXXI, vol. III: 338); o alude al sueño premonitorio de Hécuba - sobre el incendio y destrucción de Troya - para narrar el presagio onírico que tuviera García de Montalvo, un español pasado a las Indias, que, según Oviedo, permitió a este hidalgo castellano, natural de Medina del Campo, acertar con un remedio eficaz para combatir las emponzoñadas flechas de los indios caribes (Libro VI, cap. XLVII, vol. I: 208-209).

Una vez comentados algunos de los usos retóricos y estilísticos de la alusión mitológica en la Historia general y natural de las Indias, pasaremos a estudiar otras funciones del mito menos prototípicas y a nuestro juicio de mayor interés, por cuanto tienen de acento personal y de variante de época, sumamente relevantes por tanto para acercarnos al pensamiento y personalidad de nuestro cronista.

\subsection{Función política de la alusión mitológica}

\subsection{Ficción y nacionalismo: Oviedo y su doble actitud ante el mito como fuente histórica.}

Según apunta Caballero López (2002: 1-2), el evemerismo vino a suponer para los historiadores medievales la ruptura de las ya de por sí débiles fronteras entre mito e historia. En esta línea, las Etimologías de San Isidoro aportan como novedad «la aceptación del principio evemerista», que «busca y encuentra en la mitología clásica héroes civilizadores y benefactores de la humanidad (Caballero López, 2002: 2) ${ }^{24}$.

En el caso de Gonzalo Fernández de Oviedo, los límites entre mito e historia se hallan definidos, por lo general, de manera mucho más clara que en la mayor parte de sus predecesores medievales, consideración ésta que no excluye el empleo de la materia mitológica, no sólo con fines retóricos - como ya hemos visto-, sino también su utilización circunstancial como fuente documental y argumentativa, siempre al servicio de unos intereses esencialmente políticos y personales.

En este sentido, podemos señalar en Fernández de Oviedo una doble actitud ante el valor del mito como fuente histórica:

\footnotetext{
${ }^{24}$ Sobre el papel de San Isidoro como difusor del evemerismo, véase Seznec (1983: 21-22).
} 
- Primera actitud: los mitos grecolatinos deben interpretarse como «metáforas» que «reducidas a la historia cierta, son unas burlas y niñerías» ${ }^{25}$. Su valor, por tanto, como fuente documental no debe ser tenido en cuenta o al menos su peso debe estar muy por debajo de lo empíricamente comprobable. A esta consideración metodológica, podríamos decir científica, que concede al mito una función esencialmente estilística a la hora de elaborar el discurso histórico, debe añadirse cierta prevención en contra del mundo clásico, actitud presente en Oviedo y en otros autores españoles de los siglos XV y XVI.

A los versos de un Jorge Manrique en sus Coplas $^{26}$, a las palabras de un Rodríguez de Montalvo en el prólogo del Amadís ${ }^{27}$, corresponde Fernández de Oviedo con su «Dejemos las historias pasadas e volvamos a las presentes « (Libro VI, cap. VIII, vol. I: 156), convencido como está de que las verdaderas fuentes de su Historia no se encuentran en lo libresco, sino en la experiencia ${ }^{28}$.

Desde este punto de vista, considerado el mito como ficción o en cualquier caso materia no rigurosamente histórica, Fernández de Oviedo se permite utilizarlo incluso como recurso al servicio de su humorismo, rasgo éste del estilo del cronista sobre el que ya pusiera su acento Gerbi (1978: 466-475).

Así, al describir Oviedo algunas particularidades de los ritos funerarios de las gentes de la gobernación de Venezuela, explica cómo tras proceder a la cremación del cadáver, los indios caquitios tienen por costumbre preparar «cierto brebaje, que ellos llaman mazato (...) y echan en ellos los huesos del difunto molidos, y revuélvenlo mucho y bébenlo todos « ([HGNI, Libro XXV, cap. IX, vol. III, 31). Y añade, trayendo a colación el mito de Artemisa y Mauseolo:

«Esta es la mayor honra y solemnidad de obsequias que entre ellos se puede hacer (...); de manera que todos quieren ser su sepoltura, para que no se piense Artemisia que hizo mucho en tragarse las maritales cenizas, como dice Joan de $\mathrm{Mena}^{29}{ }_{\text {» }}$ ([HGNI], Libro XXV, cap. IX, vol. III, 31-32).

Conforme a esta primera actitud que acabamos de ilustrar, el mito carece para Fernández de Oviedo de credibilidad alguna - como fuente histórica, se entiende - ; otro

${ }^{24}$ Sobre el papel de San Isidoro como difusor del evemerismo, véase Seznec (1983: 21-22).

${ }^{25}$ [HGNI], Libro XX, proemio, ed. Pérez de Tudela (1959: 212-213). Es preciso señalar por otro lado que no hemos hallado en la Historia de Oviedo trazas de interpretación moral de los mitos.

${ }^{26}$ «Dexemos a los troyanos / que sus males no los vimos / ni sus glorias/ dexemos a los romanos / aunque leemos y oímos / sus estorias», Jorge Manrique, Poesías completas, ed. Pérez Priego (1990: 161).

27 «Bien se puede y debe creer aver habido Troya y ser cercada y destruida por los griegos (...), mas semejantes golpes que éstos, atribuyámoslos más a los escriptores, como ya dixe, que aver en efecto de verdad passados", Garci Rodríguez de Montalvo, Amadís de Gaula, ed. Cacho Blecua (1991: 222-223).

28 «Todos estos libros están divididos según el género e calidad de las materias por donde discurren: las cuales no he sacado yo de dos mil millares de volúmines que haya leído, como en lugar suso allegado Plinio escribe» sino de los «dos mil millones de trabajos y necessidades e peligros, e veinte e dos años e más que ha que veo y experimento por mi persona estas cosas, sirviendo a Dios e a mi rey en estas Indias, y habiendo ocho veces pasado el grande Mar Océano» [HGNI], Libro I, cap. I, ed. Pérez de Tudela (1959: vol. I, 11).

${ }^{29}$ Se refiere Fernández de Oviedo a la copla LXIV del Laberinto de Fortuna de Juan de Mena: « A ti, muger vimos, del gran Mausseolo / tú que con lágrimas nos profetizas (...)», ed. Pérez Priego (1989: 93). Oviedo dice tomar el mito - «la historia de la reina Artemisia y el rey Mauseolo»- de Estrabón. 
proceder bien distinto es el seguido cuando se presenta la oportunidad de aprovechar la materia mitológica con una clara intención política y cortesana.

- Segunda actitud: el mito se convierte en fuente histórica cuando se trata de «probar la antigüedad de España, de su población y de la institución más preciada por la mayoría de los historiadores, la monarquía» (Caballero López, 2002: 3). Se adhiere así Oviedo a una línea historiográfica - ya antigua, pero aún exitosa en su época - , que tiene su arranque, a través de San Isidoro, en la Historia de rebus Hispaniae de Jiménez de Rada (siglo XIII), prosigue con Alfonso X -Estoria de España- y encuentra eco abundante en varios historiadores del siglo XV, «apologistas de la monarquía» (Caballero López, 2002: 12), tales como Alfonso de Cartagena y Rodrigo Sánchez de Arévalo.

De este modo, para Fernández de Oviedo, Túbal fue el primer rey de España; su hijo y segundo monarca fue Hibero, Brigo fue el cuarto rey - el nombre del tercero se omite - y así, a través de diversas fuentes, prosigue la nómina hasta el décimo rey, Hispán, hijo de Hispalo y nieto de Hércules Libio, «que fue, según Beroso dice, antes que Troya se edificase, doscientos e veinte e tres años, e mil e setecientos e diez antes quel Salvador del mundo viniese» ([HGNI], Libro I, cap. III, 18).

Semejante lista dista mucho de ser ejemplo único en la Historia general y Natural de la Indias, pues a lo largo de ella Oviedo incide en la glosa reiterada de todo este material mítico que pretende explicar los orígenes de España. Se trata, como afirma Caballero López (2002: 23) del empleo del mito «para la formación de un imaginario patrio cuyos rasgos fundamentales eran la antigüedad e identidad nacional; un imaginario del que se sirvieron con vistas de legitimación y propaganda las distintas casas reales, promotores principales - no debemos olvidarlo- de las empresas historiográficas».

Como anillo al dedo viene esta aclaración a la hora de considerar el uso nacionalista y político que Fernández de Oviedo hace de estos mitos fundacionales. Aunque "contra tales invenciones y filiaciones fabulosas se alzaron ya en el siglo XV los historiadores con más conciencia crítica, o mayor autonomía intelectual, (...) al parecer no con demasiado éxito» (Caballero López, 2002: 23), el compromiso de Oviedo como cronista de Indias y su formación cortesana, siempre dispuesta a contentar a la realeza, le llevan no sólo a incluirlos en la Historia, sino a amplificarlos a través de su pretendida demostración de que Las Antillas no eran otra tierra que las antiguas Hespérides, tierra del mítico Hespero, duodécimo rey de España ([HGNI], Libro I, cap. III), tesis ésta que aseguraba el derecho de la corona en Las Indias a travês de «documentos diplomáticos de insuperable antigüedad» (Gerbi,1978: 327).

La doble actitud de Fernández de Oviedo ante la materia mitológica como fuente histórica constituye una muestra más de su nacionalismo intelectual, actitud que Hernández Sánchez-Barba (1982: 47) ha calificado de «variante de época», ambivalencia ésta que puede extenderse en general a su postura ante lo clásico y en particular hacia lo romano, «de tal manera que se produce en Oviedo respecto de Roma una dialéctica entronque-ruptura en la que, desde luego, es la ruptura la que se impone» (González, 1983: 340).

Defensor de la superioridad del imperio español sobre cualquier otro -incluido el romano-, Fernández de Oviedo aprecia lo aristocrático de Roma y sin embargo se esfuerza en desmitificarla subrayando esa «relación de superioridad a favor de España en su comparación con Roma» (González, 1083: 339). Se trata de la sustitución de un mito, Roma, por otro, España, opción que tiene su reflejo en el empleo de la materia mitológica grecolatina para engrandecer la gesta descubridora de los españoles en las Indias. 


\subsection{2.- La mitificación de la gesta española en las Indias: el sobrepujamiento}

Escribe Fernández de Oviedo en la segunda parte de su Historia:

«Me parescen cosa ridícula las grandes peregrinaciones de la navegación que de aquellos griegos se escriben por gran cosa, así como ir de Grecia a Frigia e Troya, e como venir Eneas de Troya a Italia, e como eso que de Ulixes se encaresce que anduvo vagando (...). Todo lo que Ulixes navegó en su vida, es mucho menos que venir desde España a nuestras Indias; e por luengo e dificultoso e costoso que es este camino» ([HGNI], Libro XXXI, proemio, vol. III: 363).

Tras la cita anterior, explica el cronista el siguiente caso: un simple mercader de Santo Domingo, de nombre Francisco Hernández, fue invitado como padrino a la boda de un amigo en Sevilla. Amigo de sus amigos, Hernández y su mujer parten en una nao, llegan a Sevilla, asisten a la celebración y se vuelven a La Española, muestra pues de heroicidad cotidiana, casi de chascarrillo, que tanto empequeñece en opinión de Oviedo las hazañas náuticas de un Jasón o un Ulises.

Aplicado a un caso extremo como éste, la comparación entre las antiguas gestas de los héroes y la vida de los españoles en América casi parece más humorística que política; sin embargo, al emplearse para subrayar los logros de un Magallanes, de un Cabeza de Vaca o del propio Cristóbal Colón, el paralelismo aumenta notablemente su carga retórica, como elemento que contribuye a la mitificación de los españoles y sus gestas.

Como escriben Lacarra y Cacho Blecua (1990: 35), «desde un plano literario, el entusiasmo por el descubrimiento y conquista de las Indias propicia el desarrollo de un tópico retórico, conocido con el nombre de sobrepujamiento, mediante el cual unas hazañas o personajes, los españoles, sobrepasan lo conocido de la antigüedad».

El empleo del sobrepujamiento, a la vez como recurso retórico y de engrandecimiento de lo español, alcanza un extenso desarrollo en la Historia general y natural de Fernández de Oviedo. Se trata, por otro lado, de realzar el valor de los acontecimientos de América frente a las campañas europeas del Emperador, a las que sin duda el monarca y la propia población peninsular concedían mayor atención e importancia (Lacarra y Cacho Blecua, 1990: 35$)^{30}$.

Acostumbrado como estaba Oviedo a las largas y arriesgadas travesías transoceánicas, sufridor en sus carnes de penosos naufragios, como el que le arrojó a las costas del Mar del Norte, camino de Bruselas (1515), el sobrepujamiento alcanza especial eco en su Historia a través del desarrollo de un tema, el de la navegación. Ya Gerbi (1978: 325) estudió la comparación entre la nao Victoria y la nave Argos, que hace exclamar a Oviedo: «Calle la nao de Argos, pues vimos tiempo ha, la nao nombrada la Victoria, que circuló el universo en el descubrimiento de la Especiería por aquel famoso Estrecho que el capitán Fernando de Magallanes enseñó» ([HGNI], Libro XXXI, proemio, vol. III, 363).

${ }^{30}$ Ecos de este descontento por el papel secundario que los asuntos de América ocupaban en la política imperial, los oímos en boca del propio Oviedo en no pocas ocasiones, incluso en la propia Historia. Como muestra, valga esta sutil cita acerca de la desaprovechada riqueza natural de la Isla Española: «si un príncipe no toviese más señorío de aquesta isla sola, en breve tiempo sería tal que hiciese ventaja a las islas de Secilia e Inglaterra: porque lo que aquí sobra, a otras provincias haría muy ricas» [HGNI, Libro III, cap. XI, ed. Pérez de Tudela (1959, vol. I: 78). 
De este modo, poco parece agradar al sufrido navegante toda aquella travesía de Jasón en busca del vellocino de oro; él que ya por entonces había ocho veces pasado «el grande mar océano», recuerda airado la aventura de los argonautas y no deja títere con cabeza:

« $\mathrm{Oh}$ renglones perdidos y fábulas de poetas que encarescéis y pintáis y sublimáis ese viaje de Jasón yendo a buscar aquel vellocino de oro a la isla de Colcos, y os desveláis novelando e pintando metáforas y vanidades, diciendo que le guardaba un dragón que nunca dormía, e dos toros indómitos que echaban ferviente fuego por las narices, e otras cosas fictas e de poco fructo; e para la cosa en una putería o hechicería de Medea, y en la crueldad de matar al hermano Absircio con dolor e mala vejez del padre, por huir con su enamorado! E por aquí va Ovidio ensartando disparates, que venidos al alegórico senso todo es poco, e indigno de tanta memoria como ha que turan esas ficciones ${ }^{31}$.

La verdad se alza ante el mito a la hora de narrar la aventura española en las Indias, pues «las cosas de que aquí se tracta, son en sí muy grandes e peregrinas, e que basta narrarlas llanamente e sin metáforas, por ser tan singulares y nuevas e conformes a la verdad, e tan sin obligación de afeite , ni corolario de fábulas» ([HGNI], Libro XXXI, proemio, vol. III, 364).

Pese a ello, propone Oviedo que se erija una estatua de oro con la figura de Colon, similar a la del templo de Delfos, pues «muy mejor la meresce» el Almirante ([HGNI), Libro VI, cap. X, vol. I, 167); pide silencio a «los pregoneros de Theseo, aquel laberinto y su Minotauro, pues que, sabida la verdad, esas metáforas» son «niñerías si se cotejan y traen a comparación de los que en estas Indias nuestras se ha visto» ([HGNI], Libro XX, proemio, vol. II: 213); o engrandece la odisea de Cabeza de Vaca afirmando: «Buscad esa peregrinación de Ulixes, o esa navegación de Jasón, o los trabajos de Hércoles, que todo eso es ficciones e metáforas, que entendidas como se deben entender, no hallaréis de qué os maravillar, ni son comparación igual con los trabajos de estos pecadores, que tan infelice camino e fin hicieron» ([HGNI, Libro, XXXV, cap. III, vol. IV: 299).

De este modo, si el evemerismo transformaba la naturaleza de dioses y héroes en simples mortales, protagonistas de hechos grandiosos, el sobrepujamiento engrandece la condición de los nuevos héroes de Indias, mitificando así la historia del descubrimiento, conquista y población españoles en América.

\subsection{El mito clásico y la descripción del Nuevo Mundo}

Como es bien sabido, el redescubrimiento de la antigüedad grecolatina inherente al Renacimiento lleva aparejado el esfuerzo de no pocos intelectuales por conciliar y armonizar, en la medida de lo posible, el mundo cristiano y el pagano.

Este intento de conciliación de dos mundos relativamente alejados adquirirá dimensiones absolutamente nuevas cuando ya no sean dos los universos que traten de ser

${ }^{31}$ [HGNI, Libro XLVII, cap. VI, ed. Pérez de Tudela (1959, vol. V: 148). Pese a no encarnar el papel de detractor extremo de la literatura de ficción, actitud presente en un Luis Vives, el erasmismo de Oviedo le lleva a rechazar estas ficciones alejadas de la verdad con similar criterio al empleado a la hora de vituperar el género de caballería. 
armonizados, sino tres, pues habrá que añadir al orbe conocido un sin fin de nuevas tierras y pueblos recién descubiertos a los ojos de los europeos.

Se trata evidentemente de un problema nada simple, extensísimo para ser tratado en un artículo de las características de éste, pues en él tienen cabida aspectos muy diversos y en ocasiones sumamente polémicos, tales como la visión y consideración del indio por parte de los cronistas, en nuestro caso por Fernández de Oviedo.

Entra en juego además la ya apuntada actitud del autor de la Historia ante la antiguiedad clásica, una actitud compleja que «sufre la influencia de su patriotismo antirromano, de su doliente debilidad en el conocimiento de la lengua de Cicerón y de su desprecio por la tradición, cuando la experiencia directa es posible» (Gerbi, 1978: 319).

Por todo ello, en el presente apartado nos contentaremos con señalar algunas de las funciones que cumple el mito clásico en la Historia natural y general como elemento coadyuvante a la descripción de las tierras y pobladores del Nuevo Mundo.

\subsubsection{El mito clásico y la visión del indio}

Uno de los problemas - a mi entender, tal vez el principal - con el que se enfrenta la extensísima Historia de Gonzalo Fernández de Oviedo como objeto de estudio, es la existencia de una serie de rígidos juicios de valor sobre ella, en no pocos casos verdaderos tópicos y prejuicios, tendentes a simplificar y trivializar la enorme complejidad que la obra encierra.

Así, pese al nacionalismo de Oviedo, en la Historia general y natural no sólo hay glorificación de lo español, asimismo hay crítica - y no poca, ni edulcorada - de todo el proceso colonial y de los propios españoles (Coello de la Rosa, 2001); del mismo modo, pese a las voces de Las Casas, no todo en el indio es malo para Oviedo, que nunca negó al indígena en sus escritos la cualidad esencialmente humana, la razón (Vázquez Vera, 1957: 495).

Dejando de lado problemas tan complejos y polémicos, señalaremos que en la visión del indio presente en la Historia entran a menudo en juego las referencias a la Antigüedad y sus mitos, estableciéndose cierto paralelismo entre el indígena y los gentiles, comparación ésta de la que el nativo americano sale más bien favorecido o al menos justificado a los ojos de los europeos de la época.

Podemos distinguir tres temas fundamentales en los que Oviedo dirige su mirada a la antiguiedad grecolatina y sus mitos para describir el mundo del indio:

- El tema de los ritos religiosos y las creencias indígenas. «Mucho quieren parescer las fábulas de los indios a las de los antiguos en sus templos e idolatrías» ([HGNI], Libro XLV, cap. XI, vol. V: 67). Así arguye Fernández de Oviedo al comparar el oráculo indígena de Pachacama con el oráculo de Delfos.

Según el cronista, las creencias y ritos religiosos de los indios y los antiguos deben ponerse a un mismo nivel y por tanto no constituyen motivo de especial escándalo, ya que «si miramos las cosas de los gentiles en este caso, por tan profanas y diab6licas las tenemos como las de nuestras Indias» ([HGNI], Libro XXXIII, cap. XLVI, vol. IV: 221).

Tal vez el ejemplo más jugoso de esta actitud se encuentre en el establecimiento de un claro paralelismo entre el panteón azteca y el romano ([HGNI], Libro XXXIII, cap. XLVI, vol. IV: 221), que Oviedo presenta con estas palabras: 
«Había otros sesenta cúes a la redonda del que es dicho, a manera de iglesias o templos comunes e perrochias, adonde iban los otros señores inferiores e gente más baja e plebea; pero el mayor, con otros tres oratorios, tenía Montezuma, en que sacrificaba al honor de cuatro dioses que él tenía, o ídolos, que a uno tenía por dios de la guerra, como los gentiles a Marte; e a otro honraba e sacrificaba como a dios de las aguas segund los antiguos a Neptuno; otro adoraba por dios del viento, segund los perdidos gentiles a Eolo; e otro acataban por su soberano dios, y éste era el sol (...). También tenían otros dioses; e a uno hacían dios de los maizales, e le atribuían la potencia de la guarda e multiplicación de ellos, como a Cerere los fabulosos poetas e antiguos gentiles».

Como escribe Gerbi (1978: 321), «el argumento es tan nuevo y tan fuerte, que casi no habrá apologista del indio que no lo haga suyo, echándolo a perder a menudo con la exageración de poner a los indios, bautizados o ingenuos salvajes, por encima de los incrédulos y crueles paganos».

- El tema del canibalismo y los sacrificios humanos. Las costumbres antropófagas y los ritos de sangre que Oviedo describe en determinados pueblos indígenas habrían de producir indiscutiblemente el rechazo y la incomprensión por parte de los lectores, por supuesto europeos, de la Historia. Sin embargo, como recuerda Fernández de Oviedo, tanto el canibalismo como los sacrificios humanos a la divinidad se dieron en Europa en la Antigüedad:

«¿Más que diremos, que en el medio del mundo, o lo mejor dél, que es Italia, y en Secilia, fueron los que llamaron cíclopes y los lestrigones? Y también de la otra parte del Alpe se sacrificaban hombres, segund Plinio escribe» ([HGNI], Libro VI, cap. IX, vol. I, 169).

En efecto, los flecheros caribes son aficionados a la carne humana, «excepto los de la isla de Boriquén», pero no se olvide que «aquesto mismo dice Plinio que hacen los antropófagos en Scitia, (...) que «demás de comer carne humana, beben con las cabezas o calaveras de los hombres» ([HGNI], Libro II, cap. VIII, vol. I: 35 ).

- El tema de los inventos. Si bien es verdad que en los métodos historiográficos seguidos por Fernández de Oviedo tienen cabida tanto las fuentes escritas como la información que proporciona la experiencia directa, no es menos cierto que cuando lo libresco entra en conflicto con lo empírico, Oviedo no muestra el más mínimo reparo en corregir a sus modelos clásicos. Buena prueba de ello es el que nosotros hemos denominado «tema de los inventos», que ya señalara Gerbi (1978: 320), consistente en desmentir la autoridad de los antiguos, esencialmente de Plinio, en todo aquello que se refiere a la atribución de diversos inventos a distintos personajes mitológicos.

Así, afirma Plinio que «Scythe, hijo de Jupiter, halló el arco y las saetas, y otros las atribuyen a Perseo, y el dardo con amiento lo inventó Etholo, hijo de Marte. Las velas, dice asimismo Plinio que halló Ícaro para navegar; e el árbol e entenas, Dédalo» ([HGNI], Libro VI, cap. XLV, vol. I, 205). A lo que Oviedo responde con un rotundo «no quiero creer a Plinio», «pues veo que en estas nuestras Indias - que no es menos antigua tierra en su creación, ni más moderna gente que esos inventores que se han nombrado de suso - en muchas partes, acá, son comúnmente flecheros los indios, y no se puede probar ni se debe creer que lo aprendieron de Scythe ni de Perseo» «([HGNI], Li- 
bro VI, cap. XLV, vol. I, 205) y prosigue desmintiendo la autoría mitológica del resto de inventos mencionados.

\subsubsection{El mito y la geografia clásica en la descripción de las nuevas tierras}

No querríamos terminar esta aproximación a la presencia y función del mito en la Historia general y natural de Oviedo, sin hacer mención al peso que alcanzan tanto el mito, como sobre todo la presencia de la geografía del mundo antiguo en la descripción de las nuevas tierras.

De este modo, al describir los volcanes de las Indias, asistimos a la comparación con el Etna, el monte Ténaro o el monte Vulcano, como Oviedo parece llamar al Vesubio. En otro pasaje, las muchas islas que afloran desde el cabo de Santa María a la costa de Labrador se asemejan a las del Egeo, todo ello sin que falte el uso del mito para dar nombre a los nuevos enclaves descubiertos, como la Isla de las Amazonas ([HGNI], Libro XXI, cap. VIII, vol II, 330) o la Isla de la Gorgona, así bautizada por los españoles «por las muchas serpientes que en ella hay» ([HGNI], XLVI, cap. XVII, vol. 5: 96).

\section{Conclusiones}

Brevemente y de manera sintética las conclusiones fundamentales del presente artículo son las que siguen:

a. La transmisión de la materia mitológica presente en la Historia general y natural de las Indias ha tenido lugar, esencialmente, a través de fuentes indirectas, tanto latinas como romances, españolas e italianas en este último caso.

b. Gonzalo Fernández de Oviedo emplea el mito con una clara función retórica, encaminada a reforzar la presencia del argumento de autoridad en su Historia y a elevar con ello el estilo de la misma. Estas alusiones, aunque presentes a lo largo de toda la obra, se concentran de manera especial en los prólogos o proemios, en los que la presencia de Carlos V como receptor se hace más perceptible.

c. La consideración del mito como fuente histórica provoca en Fernández de Oviedo una doble actitud:

- por una parte, considera al mito como ficción, por lo que carece de valor como fuente documental.

- sin embargo, el mito se convierte en historia para probar la antigüedad de España y sus pobladores y el derecho de la monarquía sobre las Indias. De esta manera, la presencia del mito cobra una clara función política.

d. A medio camino entre lo retórico y lo político, destaca en la Historia el empleo del sobrepujamiento. Si el evemerismo suponía la desmitificación del mito, el sobrepujamiento es en cierto modo un proceso inverso que tiene como objeto a algunos españoles pasados a las Indias. 
e. En la Historia general y natural Oviedo suele dirigir la mirada al mundo antiguo justo en el momento de describir el nuevo. El mito hace acto de aparición para contribuir a la construcción de una visión familiar del indio y la naturaleza.

5. ÍNDICE DE REFERENCIAS MITOLÓGICAS EN LA Historia GENERAL Y NATURAL DE LA INDIAS $^{32}$

Adriático, mar: I, 40; III, 334; IV, 120.

Alcides: V, 127.

Amazonas, isla de las: II, 330 .

Antenor: II, 213; IV, 120.

Apolo: I, 217; V, 67.

Aquiles: I, 18; III, 363.

Arcadia: provincia: I, 19, 291; II, 49; III, 189.

Artemisia, reina: III, 31, 408.

Baco: I, 217, 275.

Cadmo: I, 17, 156; IV, 143.

Calidonia, mar de: IV, 393.

Ceres, diosa: IV, 221, 419.

Cíclades, islas: V, 67.

Circe: I, 219.

Creúsa, hija de Príamo: II, 213.

Dánao: I, 166.

Dédalo: I, 205; 217.

Delfos: I, 167; V, 67, 68 .

Deucalión: I, 150.

Diana: III, 408.

Diomedes, isla de: I, 249.

Efesios, montes: IV, 393.

Éfeso, ciudad: I, 158; III, 409.

Egeo, mar: I, 40; II, 336.

Elena de Troya: I, 208.

Elisa Dido, reina: III, 160.

Eneas: II, 213; III, 363.

Eolo: IV, 221.

Epidauro o Durazo, ciudad: I, 218.

Epiro, reino: I, 18; III, 178; IV, 269.

Etna o Mongibel, volcán: I, 8; IV, 26, 233, 359, 389, 393.

Eubea, isla: I, 42.

Eurice, hijo de Áyax: IV, 270.

Euxino, mar: II, 288, 336.

Evémero: III, 196.

${ }^{32}$ Citamos por la edición de Pérez de Tudela (1959), señalando el volumen y página en que se encuentra la alusión mitológica. 
Frigia: I, 18; III, 363; V, 68.

Ganímedes: III, 338.

Gorgona o Felipa, isla: I, 282; III, 171; V, 11, 97, 222.

Héctor: III, 53.

Hécuba: I, 208.

Hércules: I, 18, 40; II, 40, 41, 295; IV, 299; V, 127.

Hesiodo: I, 158.

Hespérides, islas: I, CXX, 13, 17, 19, 20, 36; II, 86, 87, 189; III, 330.

Hesperis: IV, 393.

Hespero, rey: I, XLII, CXX, 17 a 20; III, 330; IV, 42.

Hispán, rey: I, 18, 19; IV, 98.

Homero: I, 142, 158; III, 196, 362; IV, 143, 258.

Ícaro: I, 205.

Ilia, vestal: IV, 248.

Jasón: I, 18, 166, 199; II, 212, 218, 240; III, 178; IV, 299; V, 148.

Jonio, mar: I, 249.

Juno: IV, 221.

Júpiter: I, 18, 63, 205; II, 414; III, 196, 331, 408; IV, 221; V, 56.

Lavinia: II, 213.

Lestrigones, nación: I, 169.

Libia: V, 136.

Licaonia, provincia: III, 293.

Lidia: I, 17; III, 408.

Marte: I, 205; IV, 221, 248, 419.

Mauseolo: III, 408.

Medea: I, 199; II, 212, 240; V, 148.

Medusa: IV, 299.

Midas: rey: $\mathrm{V}, 212$.

Minos: rey: III, 71.

Mitrídates: III, 296; IV, 125.

Narciso: III, 149.

Neptuno: IV, 221, 419; V, 212.

Néstor: I, 142.

Olimpo, monte: III, 409.

Ovidio, Publio: I, 135, 150; II, 28, 212, 314; III, 196, 310, 338; IV, 393; V, 148, 212, 322.

Paris: I, 208.

Paris, golfo de: III, 258; IV, 343.

Patroclo: III, 363.

Penélope: III, 363; IV, 285.

Peritoo (Piritoo): I, 142; II, 295.

Pirro: I, 18, 146.

Prometeo: IV, 421.

Proserpina: I, 205.

Rea, diosa: IV, 248.

Saturno: III, 196.

Scite: I, 63 
Scitia, reino: I, 18, 35; II, 214; III, 296.

Semíramis: I, 120; III, 298, 408.

Silvia, vestal: IV, 248.

Tesalia, reino: I, 142; 219; II, 77 .

Teseo, I, 142, 218; II, 212.

Troya: I, 18, 208, 219, 288; III, 330, 363; IV, 120, 143, 269.

Túbal: I, 18; II, 213.

Ulises: I, 219; III, 196, 363; IV, 285, 299.

Virgilio, I, 150, 209, 226, 263; IV, 393.

Vulcano, dios: IV: 419.

Vulcano, monte: I, 8; III, 408; IV, 26, 79, 162, 255, 333, 356, 359, 360, 390, 393.

\section{6.- BiBLIOGRAFÍA}

AMADOR DE Los RÍS, JosÉ (ed.) (1851): Gonzalo Fernández de Oviedo, Historia general y natural de las Indias, Academia de la Historia, Madrid.

Arcaz Pozo, Juan LuIs (2002): «Mitología clásica en los poemas de los siglos XIV y XV «, XIII Coloquio internacional de Filología griega: influencias de la mitología clásica en la literatura española de los siglos XIV y XV, Área de Filología Griega de la UNED, Madrid.

Asensio, Eugenio (1949): «La carta de Gonzalo Fernández de Oviedo al Cardenal Bembo sobre la navegación del Amazonas», Revista de Indias, 37-38, págs. 569-577, CSIC, Madrid.

Ballesteros Gaibrois, Manuel (1958): Vida del madrileño Gonzalo Fernández de Oviedo, Instituto de Estudios Madrileños, Madrid.

- (1981): Gonzalo Fernández de Oviedo, Fundación Universitaria Española, Madrid.

Caballero López, José (2002): «Presencia y función del mito en la historiografía española de los siglos XIV y XV", XIII Coloquio internacional de Filología griega: influencias de la mitologia clásica en la literatura española de los siglos XIV y XV, Área de Filología Griega de la UNED, Madrid.

Cacho Blecua, Juan Manuel (ed.) (1991): Garci Rodríguez de Montalvo, Amadís de Gaula, Cátedra, Madrid.

COello DE LA Rosa, AleXANDER (2001): «iIndios buenos?, ¿indios malos?, ¿buenos cristianos?: la cara oscura de las Indias en Gonzalo Fernández de Oviedo y Valdés», Revista electrónica de geografia y ciencias sociales, vol. V, $\mathrm{n}^{\mathrm{o}} 101$, http://www.ub.es/geocrit/sn-101.htm, Universidad de Barcelona.

CREsPo, ÁNGel (ed.) (1988): Francesco Petrarca, Cancionero. Sonetos y canciones, Espasa Calpe, Madrid.

DE LAMA, VícTOR (1999): «Erasmo y la lengua en la España renacentista», Edad de Oro, vol. XIX, págs. 131-153, UAM, Madrid.

Fabregat Barrios, Santiago (2001): Estudio y edición crítica del Libro de la Cámara Real del príncipe don Juan, Dir. Miguel Ángel Pérez Priego, Departamento de Literatura Española y Teoría de la Literatura, Facultad de Filología, UNED, 2001.

- (2003) «Una revisión de la obra histórica y literaria de Gonzalo Fernández de Oviedo (14781557). La edición crítica del libro de la Cámara Real del principe Don Juan (1546-1548)», en F. SÁnCheZ MiReT (ed.), Actas del XXIII Congreso Internacional de Lingüistica y Filología Románica, vol. IV, Tubinga, Max Niemeyer, pp. 89-97 
Gerbi, Antonello (1978): La naturaleza de las Indias nuevas. De Colón a Gonzalo Fernández de Oviedo, Fondo de Cultura Económica, México.

GonZÁlez, JAIME (1983): «El antirromanismo de Gonzalo Fernández de Oviedo», Revista de Indias, 43, págs. 335-342, CSIC, Madrid.

HernáNDEZ SÁNCHEZ-BARBA, MARIo (1982): «El nacionalismo intelectual de Gonzalo Fernández de Oviedo, como variante de época», Homenaje a Gonzalo Fernández de Oviedo, cronista de Indias, en el V centenario de su nacimiento, págs. 47-53, CSIC, Madrid.

KIDD, MiChael (2002): «Presencia y ausencia de mitología clásica en las farsas y églogas de Lucas Fernández», XIII Coloquio internacional de Filología griega: influencias de la mitología clásica en la literatura española de los siglos XIV y XV, Área de Filología Griega de la UNED, Madrid.

lacarra, María Jesús y Cacho Blecua, J. Manuel (1990): Lo imaginario en la conquista de América, Diputación General de Aragón y Comisión Aragonesa V Centenario, Zaragoza.

Laf́n EnTRalgo, Pedro (1979): «Fernández de Oviedo ante la naturaleza del Nuevo Mundo», Estudios sobre literatura y arte dedicados al profesor Emilio Orozco Díaz, págs. 215-230, Universidad de Granada, Granada.

LÓPEZ GRIJERA, LUISA (1995): «La retórica en la España del Siglo de Oro», Ediciones Universidad de Salamanca, Salamanca.

OTTE, ENRIQUE (1958a): «Aspiraciones y actividades heterogéneas de Gonzalo Fernández de Oviedo», Revista de Indias, 71, págs. 9-62, CSIC, Madrid.

- (1958b): «Documentos inéditos sobre la estancia de Gonzalo Fernández de Oviedo en Nicaragua», 1527-1529, Revista de Indias, XVII, págs. 627-651, CSIC, Madrid.

- (1982): «Gonzalo Fernández de Oviedo, alcaide», Homenaje a Gonzalo Fernández de Oviedo, cronista de Indias, en el V Centenario de su nacimiento, págs. 29-47, CSIC, Madrid.

PEÑa CÁMARA, JoSÉ DE LA (1957): «Contribuciones documentales y críticas para una biografía de Gonzalo Fernández de Oviedo", Revista de Indias, XVII, págs. 603-705, CSIC, Madrid.

PEREZ DE TUdela Y Bueso, JuAn (1957): «Rasgos del semblante espiritual de Gonzalo Fernández de Oviedo: la hidalguía caballeresca ante el Nuevo Mundo", Revista de Indias XVII, págs. 391-443, CSIC, Madrid.

- (ed.) (1959): Gonzalo Fernández de Oviedo, Historia General y Natural de las Indias, BAE, Atlas, Madrid.

Pérez Priego, Miguel Ángel (ed.) (1990): Jorge Manrique, Poesias completas, Espasa Calpe Madrid.

- (ed.) (2003): Juan de Mena, Laberinto de Fortuna, fundación José Manuel Lara (Clásicos andaluces, 1), Sevilla.

REAl ACADEMia EsPañola (ed.) (1956): Gonzalo Fernández de Oviedo, Libro del muy esforzado e invencible caballero Don Claribalte, edición facsímil, Espasa-Calpe, Madrid.

Río Nogueras, Alberto del (2001) (ed.): Gonzalo Fernández de Oviedo, Claribalte, Centro de Estudios Cervantinons, Alcalá de Henares.

Rodilla León, Marf́a José (ed.) (2002): Gonzalo Fernández de Oviedo, Claribalte, Universidad Autónoma de México.

SEZnEC, JEAN (1983): Los dioses de la Antigüedad en la Edad Media y el Renacimiento, Taurus, Madrid.

TURNER, DAYMOND (1971): «Los libros del Alcaide: la biblioteca de Gonzalo Fernández de Oviedo y Valdés», Revista de Indias, 89-90, págs. 327-334, CSIC, Madrid. 
URÍA RIU, JuAN (1960): «Nuevos datos y consideraciones sobre el linaje asturiano del historiador de Indias, Gonzalo Fernández de Oviedo", Revista de Indias, XX, págs. 13-29, CSIC, Madrid. VÁZQUEZ VERA, JOSEFINA ZORAIDA (1957): «El indio americano y su circunstancia en la obra de Oviedo", Revista de Indias, 69-70, págs. 483-519, CSIC, Madrid. 